\title{
Materials Challenges for the Next Century: A Concluding Note
}

The trouble with our times is that the future is not what it used to be. -Paul Valery

The best way to predict the future is to invent it.

-Alan Kay

Everything must end; meanwhile we must amuse ourselves.

—Voltaire

Calendars are human inventions to persuade us of discontinuities where none exist. Tomorrow is often not just another day, but a New Year's Day, January 1, or the beginning of a new millennium. And they provide convenient settings to get our breath back, recount the road traveled, and prepare for the journey ahead. We all use these breaks in our personal and professional lives, from New Year's resolutions to identifying the problems to pursue. All very arbitrary, when you really think about it, but very, very convenient: continuum replaced by manageable, discrete packets

At MRS, we wanted to speculate on what the new millennium would bring to our field. We were sure that there would be new inventions, of course, made of new materials with properties that we could only guess at and applications we have not even thought of. We know that the impressive economic growth of the last century could not have been sustained without materials, and we assumed that this should be the case for the new century as well. We therefore persuaded our contributors to speculate on the demands of the new century by breaking away from the confines of the present. We wanted them to be imaginative, traveling on the fringe of recklessness, and identify the societal and technical questions for which the new materials would enable the answers.

In the first article of this series, Alan Cottrell summarized the road traveled in the last century: the emergence of science of materials, a theme so admirably captured in a recent book, The Coming of Materials Science (Pergamon, Elsevier Science, Oxford, 2001), by Robert Cahn. Over a dozen articles followed, with occasional interludes on a few areas of interest. Excepting a few areas-land transportation is a glaring omission-our contributors wrote of their predictions. Some, very adventurous, assumed solutions for problems where none exist while gazing into the future, and others, more cautious, hopefully traced a gradual growth, not daring to predict discontinuities that portend radical changes. But all of our contributors identified questions to which answers should be found in this century.

The last century converted materials and their primary products into commodities, mined and manufactured in large tonnages, transported with ease across continents, and available at affordable costs. These, from steels in the beginning to silicon chips at the closing of the century, provided the wherewithal for economic growth, the like of which human society had not experienced before. But we see a message that is different for this new century: first, the fragility of the materials cycle, which we are now learning to appreciate. This

\section{Some authors, very} adventurous, assumed solutions for problems where none exist while gazing into the future, and others, more cautious, hopefully traced a gradual growth, not daring to predict discontinuities that portend radical changes.

requires us to be more diligent in the production and consumption of materials, and in the consumption of energy in making them. In the last century, in our eagerness for quantity and economy of scale, we largely neglected pollution and the degradation of our environment. Only now do we realize the enormous time and costs involved in cleaning such polluted environs and diluting the heattrapping gases in the atmosphere.

There has also been a change of focus on the properties we seek. In the last century, the properties of concern were gen- erally strength and toughness, and the electrical and magnetic behavior of materials. In this century, the challenges are in understanding and making materials, not at the bulk continuum scale, but at atomic and molecular levels, and in developing tools to see and "feel" such materials and nano products. When artifacts become diminutive, the role of imperfections becomes critical, only to vanish when the size shrinks further to atomic and molecular levels. In the past, our concerns at these levels were on calculating cohesive energy to estimate the intrinsic strength, measuring spin to determine the magnetic properties, and so on. To these lists we must now add other properties such as the capacity of materials to store or carry information by bits and bytes flawlessly, this time to build structures of knowledge.

From this series, we have learned of two other issues that warrant attention: One is the concern about educating materials scientists, especially when we cannot even fully comprehend the future from which the new materials challenges will emerge. Will our education be so molded that it continues to encourage communication across various fields, even after materials science is recognized as a distinct discipline? Who would have expected, for instance, that progress in biotechnology and robotics would depend so critically on the development of new materials, as we observe in tissue engineering and microelectromechanical systems?

The science of economics has also come of age. Utility functions, uncertainty analysis, risk assessment, and environmental-impact analysis are the new tools now available for evaluating materials for development. These are precisely the ones needed for quantitative analysis of costs and benefits in the materials cycle. Like mechanical testing and microscopy, these economic methods are here to stay in the materials scientist's tool kit.

As we conclude this series, we are only too aware of the many questions we refrained from asking. We hope that you, the readers, will remedy this omission with letters, comments, and other contributions. As we said in our initial editorial, we have found this journey heady enough for us.

V.S. ARUNACHALAM AND E.L. FLEISCHER 


\section{Materials Challenges for the Next Century}

\section{A special series published in MRS Bulletin that speculates on the role}

of materials in society in the coming century and beyond.

V.S. Arunachalam and E.L. Fleischer, Coordinators www.mrs.org/publications/bulletin/21 stcen/

Introduction

E.L. Fleischer, MRS Bulletin

December 1999

Introduction

V.S. Arunachalam, Carnegie Mellon University

January 2000

\section{A Centennial Report}

Looking back on 100 years of materials development

A. Cottrell, Cambridge University

February 2000

\section{Editorial}

V.S. Arunachalam, Carnegie Mellon University

E.L. Fleischer, MRS Bulletin

September 2000

\section{Materials Science 2100?}

R.R. Chianelli, University of Texas at El Paso

September 2000

\section{The Science of Things}

Unanswered scientific questions and unquestioned scientific answers in materials research and development

R.W. Cahn, Cambridge University

September 2000

\section{A Concluding Note}

V.S. Arunachalam, Carnegie Mellon University

E.L. Fleischer, MRS Bulletin

December 2001

Posterminaries, Y20K-Looking Back

E.N. Kaufmann, Argonne National Laboratory

November 1999

Materials for the Human Habitat

T.N. Gupta, Building Materials and Technology

Promotion Council, India

April 2000

Information Technology: A Play of Materials

P. Chaudhari, IBM

July 2000

The Future of Medicine: Biomaterials

H.R. Piehler, Carnegie Mellon University

August 2000

Structural Materials in Aerospace Systems

D. Banerjee, Defence Metallurgical Research Laboratory

Hyderabad, India

March 2001

Materials for the Power Industry

B.L. Eyre, University of Oxford

J.R. Matthews, University College London and European Union Tacis Program July 2001

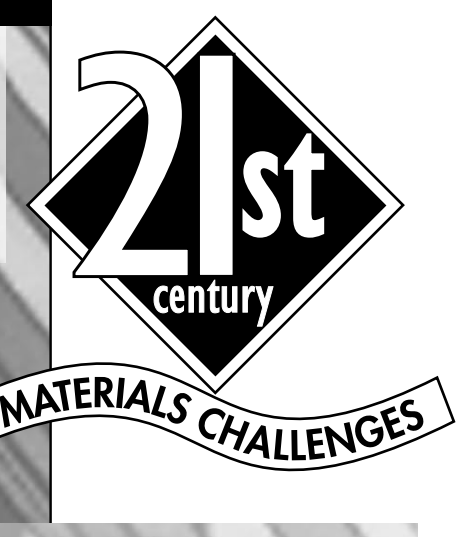

Does Integrated-Circuit Fabrication Show the Path for the Future of Mechanical Manufacturing?

F.B. Prinz, A. Golnas, and A. Nickel, Stanford University October 2000

Self-Assembled Materials

W.M. Tolles, (Retired) Naval Research Laboratory October 2000

Yashoda's Vision: Microscopy at All Levels S. Ranganathan, Indian Institute of Science February 2001

Materials and the Global Environment: Waste Mining in the 21st Century R.U. Ayres, INSEAD, France

J. Holmberg, Chalmers University of

Technology and Göteborg University in Sweden

B. Andersson, University of Technology and

Göteborg University in Sweden

June 2001

Materials Education for the New Century M.C. Flemings and S. Suresh,

Massachusetts Institute of Technology November 2001

Development Priorities for African Materials Research Education in the Next Hundred Years

A. Kebede, North Carolina A\&T State University

A.Z. Msezane, Clark Atlanta University

November 2001

Perspectives of Materials Education Development in Russia for the New Century

Yu.D. Tretyakov, Lomonosov Moscow State University, Russia November 2001

Market Drivers for Materials and Process Development in the 21st Century

F.R. Field III, Massachusetts Institute of Technology J.P. Clark, Massachusetts Institute of Technology

M.F. Ashby, Cambridge University

September 2001 